May - 2021

\title{
Book Review: Guidelines on the Development of Open Educational Resources Policies
}

Authors: Fengchun Miao, Sanjaya Mishra, Dominic Orr, and Ben Janssen: (UNESCO and Commonwealth of Learning (COL), 2019, 107 pages) ISBN: 978-1-894975-97-1

Reviewed by: Irem Demirbag and Sedef Sezgin, Anadolu University

UNESCO and the Commonwealth of Learning (COL) have published these guidelines as a joint effort. They include steps for evaluating, assessing, designing, and implementing OER initiatives and policies. It is comprised of seven chapters, including the concept of OER; policy visions; frameworks; masterplans; implementation plans; and launching strategies. It also includes the purpose, background information, and references, with practical examples. At the end of each chapter, specific tasks are set for the policymaker to help develop a final OER policy.

In Chapter 1, the concept of open educational resources (OER) is provided, and the resources are placed in the context of achieving the Sustainable Development Goal (SDG 4): Education For All.

Chapter 2 outlines the educational challenges to achieving SDG4, such as expanding access, enhancing inclusion and diversity, promoting gender equality, supporting high quality education, and providing opportunities for lifelong learning. To deal with these challenges, the authors present across-the-board solutions. It then discusses the reasons or ideas for using OER to tackle the complexities of teaching and learning systems, as well as enhancing or even transforming education.

Chapter 3 presents the principles of a policy's scope and scale, determines the level at which the policy is to be set, and identifies the areas of the education system that will be included in the policy. This chapter also provides a framework for guiding decisions on scope and scale, and addresses policy choices regarding possible regulatory requirements as well as other resources to aid OER implementations.

Chapter 4 introduces four key strategic areas where there are significant gaps that need to be addressed. These strategic areas include the current knowledge level of stakeholders, providing learning materials, possible technical and regulatory barriers to the use of OER, and the type and content of training and support for teachers and instructors.

Chapter 5 presents the main building blocks that an OER policy should include, such as adopting an open licensing framework, integrating OER into curriculum, aligning quality assurance procedures, etc. The reader will have completed a complete masterplan draft for OER by the end of this chapter and will be ready to consider an implementation strategy.

Chapter 6 reveals the five components of the policy implementation plan. The operational task of this plan is to use specific methods, allocate resources, involve stakeholders, and coordinate the implementation of the master plan. It also involves developing an organizational structure for policy 
governance and collaboration, as well as international cooperation to facilitate peer learning and the exchange of ideas.

In the final chapter, the authors argue that the introduction of a policy requires coordinating core activities sponsored by high-level approval, engaging different stakeholders and user groups with a view to clarifying, and communicating the policy objectives and the implementation plan.

The guide includes many resources with examples of previous OER implementations. These serve to inspire and provide information about OER related activities, organizations, and champions. The guide also includes a map website called the OER World Map that currently has over 3,00o entries from around the world (https://oerworldmap.org/resource/).

Although the guide focuses on developing a policy for OER, at the beginning of the guide there is some limited information describing OER and how they can be used. However, a first reading of this book can be complex for those who are not familiar with the subject. So, the guide recommends resources for those who need a basic understanding of OER, such as Understanding Open Educational Resources (Butcher \& Moore, 2015), A Basic Guide to Open Educational Resources (OER) (Butcher, 2011). In addition, there is online training provided by COL on Understanding Open Educational Resources that is accessible and free of charge for anyone.

Compared with these other resources about OER, this guide expands on the common issues, and focuses on policy-making steps for governments and institutions to implement OER projects. One of the principal strengths of the guide is that the chapters include tasks for the reader to complete using common concepts and design criteria, while referring to cases from all over the world. The tasks are completed by considering your own countries' circumstances and initiatives. Here is an example from the tasks: "What are the major challenges or issues your education system is facing in achieving SDG 4? Based on your understanding of OER, how can adopting OER contribute to their solution?” (p. 17).

Upon completion, anyone who has finished the tasks provided would have an extensive framework that included essential and urgent points to start developing an OER policy. Furthermore, the cases around the world that demonstrated successful OER implementations in projects and polices at the institutional or government levels encourage the reader to take action. One of the cases focuses on the considerable costs for teaching and learning materials for both education providers and learners. Using this case, the reader compares the cost of materials in given countries with his/her own country and realizes that OER can eliminate much of these costs. OER can help institutions and students internationally to cope with the rising cost of education.

According to UNESCO SDG4, everyone has the right to education, and countries have an obligation to include everyone equitably, and to ensure gender equality. Using OER can help further access to quality learning opportunities for everyone. In sum, this guide provides a comprehensive structure for governments and institutions to set out their policy vision and scope, then create and implement a policy masterplan for OER. This detailed guide on how to develop systematic and effective policies on OER can assist anyone concerned with OER implementations. SDG4 can be achieved using distance education and OER to provide inclusive and equitable quality education and promote lifelong learning opportunities for all. 


\section{References}

Butcher, N. (2011). A basic guide to open educational resources (OER). United Nations Educational, Scientific and Cultural Organization and Commonwealth of Learning. http://hdl.handle.net/11599/36

Butcher, N., \& Moore, A. (2015). Understanding open educational resources. Commonwealth of Learning. http://hdl.handle.net/11599/1013

Miao F., Mishra S., Orr D., \& Janssen B. (2019). Guidelines on the development of open educational resources policies. United Nations Educational, Scientific and Cultural Organization and Commonwealth of Learning. http://hdl.handle.net/11599/3455

Athabasca

University

(ब) (1) 